\title{
DECLÍNIO DOS CITROS: ALGO A VER COM O SISTEMA DE PRODUÇÃO DE MUDAS CÍTRICAS? ${ }^{1}$
}

\author{
RICARDO BRAGA BALDASSARI ${ }^{2}$, ANTONIO DE GOES², FERNANDO TANNURI ${ }^{3}$
}

\begin{abstract}
RESUMO - Na atualidade, a citricultura paulista enfrenta sérios problemas com o surgimento de novas enfermidades limitantes ao processo produtivo. Uma das alternativas para prevenir essas enfermidades é, seguramente, a produção de mudas certificadas, com borbulhas e sementes de assegurada qualidade genética e sanitária, produzidas em containers ou sacos plásticos, sob fiscalização dos órgãos competentes, garantindo-se, assim, a sanidade das mesmas. No entanto, tem-se verificado que grande parte do processo operacional de produção de mudas cítricas foi parcialmente adaptado da produção de essências florestais (eucalipto), onde se insere, principalmente, o emprego de tubetes com comprimento de $12 \mathrm{~cm}$. Tal prática desencadeia uma grave deformidade morfológica no sistema radical das mudas cítricas, reduzindo o seu potencial de crescimento, quando são plantadas a campo, em local definitivo. Como a principal causa desencadeadora do declínio dos citros parece ser o estresse hídrico, plantas oriundas desse sistema de produção de mudas, mostram-se muito mais vulneráveis ao estresse e, conseqüentemente, a esta anomalia. Como atualmente todas as mudas produzidas no Estado de São Paulo provêm desse sistema de produção, seguramente o declínio dos citros tenderá a ser, futuramente, muito mais freqüente e severo nos casos de combinações vulneráveis à sua ocorrência.
\end{abstract}

Termos para indexação: Citrus, declínio, porta-enxerto, muda.

\section{CITRUS BLIGHT: IS THERE SOMETHING ABOUT THE NURSERY TREES PRODUCTION?}

\begin{abstract}
ABSTRAT - Nowadays, São Paulo citrus culture faces serious problems with the outbreak of new diseases that limit the production process. One of the alternatives to prevent these diseases certainly is the production of certified seedlings, with shoot meristems and seeds of guaranteed genetic and sanitary quality, produced in containers or plastic bags, under the inspection of competent bureaus, thus assuring their health. However, it has been observed that a large part of the operational process of citrus seedling production has been partially adapted from the eucalypt production system, where, the use of plastic conic $12 \mathrm{~cm}$-long cells were originally used. Such practice entails a severe morphological deformation of the root system on citrus seedlings, reducing their growth potential after field transplanting. Because the major triggering cause for citrus decline is the water stress, plants originating from this production system are much more vulnerable to the stress and, consequently, to this anomaly. Since all seedlings produced in São Paulo State come from this system, certainly citrus decline tends to be, in the near future, much more frequent and severe in the cases of vulnerable combinations for its occurrence.
\end{abstract}

Index terms: Citrus, blight, rootstock, nursery tree.

A citricultura brasileira, não obstante a sua pujança, ressentese de vários problemas de ordem fitossanitária, muitas vezes relacionados à qualidade da muda, os quais afetam a produtividade e longevidade dos pomares. Dentre esses vários problemas, incluem-se a Gomose de Phytophthora, Clorose Variegada dos Citros, Declínio dos Citros e, ultimamente, a Morte Súbita dos Citros, uma doença por ora de etiologia desconhecida.

Atualmente, com a nova concepção no processo de produção de mudas cítricas, associada às novas tecnologias do manejo da cultura, incluindo-se a diversificação do uso de porta-enxertos, levanta-se a possibilidade potencial de que vários desses problemas estejam amenizados. Por exemplo, é de opinião quase unânime de que, com a aplicação das atuais normas de produção de mudas cítricas, restrita exclusivamente sob ambiente protegido, conforme legislação vigente, muitos desses problemas estariam resolvidos. Trata-se de um processo irreversível onde, certamente, em função da padronização e fiscalização, espera-se maior longevidade, estabilidade de produção e produtividade dos pomares. Tal potencial será alcançado, na prática, se houver equilíbrio envolvendo qualidades genética e fitossanitária do material de propagação, associado a práticas culturais adequadas. No manejo cultural, em particular, há necessidade de que o desenvolvimento da parte aérea e sistema radical da planta dêem-se de forma equilibrada e harmoniosa. Tal equilíbrio é fundamental para minimizar o problema de estresse e suas conseqüências. Assim, entende-se que, embora na nova concepção de produção de mudas cítricas prevaleça a idéia da prevenção, alguns problemas relevantes e freqüentes nos pomares citrícolas do Brasil e em particular no Estado de São Paulo, ainda perdurem. Pior ainda, não se tem dado a atenção necessária e devida, como é o caso do declínio dos citros.

\section{O declínio dos citros}

O declínio dos citros é uma alteração no desenvolvimento normal da planta, caracterizada por perdas acentuadas de folhas, excesso de brotação no tronco e em pernadas, gradativo secamento de galhos, floradas extemporâneas, deficiências acentuadas de nutrientes, especialmente zinco, mesmo em pomares adequadamente fertilizados, acúmulo de fenóis solúveis no caule, presença de obstruções amorfas nos vasos do xilema e baixa produção. Normalmente, plantas sintomáticas não morrem. Tal anomalia ocorre com mais freqüência em plantas de laranjeiras doces enxertadas em limoeiros 'Cravo', Poncirus trifoliata, limoeiro 'Rugoso', Citrus volkameriana e citranges Morton e Troyer. Considera-se como porta-enxertos resistentes e/ou tolerantes as tangerinas 'Sunki', 'Cleópatra' e laranja 'Caipira'.

O declínio dos citros foi constatado no Brasil na década de 70 (Rossetti, 2001) e atualmente, tem presença assinalada em praticamente todas as regiões produtoras. Além do Brasil, sua ocorrência encontra-se assinalada na Argentina, Uruguai e Estados Unidos, onde é designada como Declinamiento ou Fruta Bolita, Marchitamiento repentino e Blight, respectivamente. No Estado de São Paulo, estima-se que 6 a $8 \%$ das plantas são afetadas anualmente, significando que, a cada ano, mais de 10 milhões de plantas tornam-se improdutivas.

Embora o declínio dos citros seja conhecido a mais de um século, como é o caso na Flórida, EUA, não há, ainda, o diagnóstico do agente causal. A natureza etiológica do problema é controversa, encontrando-se na literatura citações quanto ao envolvimento de agentes bióticos (Burnett et al., 1982), sendo, inclusive, os sintomas reproduzidos através de enxertia de raízes (Tucker et al., 1984; Rossetti, 2001).

Segundo Berger (1998), a tentativa de explicar a transmissão de um agente infeccioso por meio da enxertia de raízes, pode ser interpretada como uma transferência de ácido abcísico (ABA) de uma raiz para outra, uma vez que esse hormônio ocorre em níveis elevados em raízes

\footnotetext{
${ }^{1}$ (Trabalho 003/2003). Recebido: 08/01/2003. Aceito para publicação: 08/07/2003.

${ }^{2}$ UNESP - Departamento de Fitossanidade, Câmpus de Jaboticabal, CEP 14884-900, Jaboticabal - SP, e-mail: ribraba@ bol.com.br e agoes@ fcav.unesp.br; fone: (016) 32092640 ou (016) 32092641.

${ }^{3}$ Eng. Agr. Casa da Agricultura de Araraquara - Rua 13 de Maio 1.352 - Araraquara - SP CEP 14802-000, fone: (016) 222-0511.
} 
de árvores sob estresse. O mesmo autor, através de revisão sobre o assunto, faz uma ampla abordagem sobre as possíveis causas dessa anomalia, tornando evidente a ausência do envolvimento de um agente biótico. Dentre essas evidências temos: 1- Não foi encontrado nenhum patógeno associado à anormalidade, mesmo após exaustivos estudos, amparados com técnicas modernas de investigação e análises, como microscopia eletrônica de transmissão e varredura, serologia, sondas de DNA, meios seletivos para isolamento em cultura pura de microorganismos e corantes específicos; 2- Os sintomas do declínio dos citros apresentam semelhança àqueles que ocorrem em outras espécies de árvores, como por exemplo, em carvalhos (Quercus spp), freixo (Fraxinus excelsio), ácer, ácer de açúcar (Acer spp), dendezeiro (Elaeis guineensis) e mangueira (Mangifera indica). O declínio destas espécies é tido como causado por fatores de natureza não patogênica; 3- O perfil de aumento da incidência do declínio dos citros, no tempo, é diferente daquele associado a várias epidemias causadas por patógenos de plantas. De acordo com Yokomi et al. (1984) e Sonoda et al. (1992), na Flórida, o progresso do declínio dos citros ao longo do tempo dá-se de forma linear, assemelhando-se a vários outros tipos de declínios, de causa não parasitária. No Brasil, de acordo com Tubelis et al. (1988), o progresso temporal da doença poderia ser descrito como uma função exponencial, divergindo dos resultados obtidos nos EUA. Nesse caso, epidemiologicamente esperava-se um progresso acentuado da doença, ocupando gradativamente todos os pomares, de tal forma que todas as plantas acima de seis anos estariam afetadas, o que não tem se dado na realidade. Tal fato suscita e fortalece a idéia da ausência de agentes bióticos associados à doença; 4- De acordo com Sonoda et al. (1992), a distribuição espacial de plantas cítricas com sintomas de declínio dá-se geralmente ao acaso, cujo perfil enquadra-se mais apropriadamente a problemas de natureza abiótica. Certamente, o envolvimento de um agente patogênico levaria, ao longo do tempo, à ocorrência na forma de agregado, fato esse não observado nas condições do Brasil; 5- Tem-se verificado que tanto na Flórida (Wutscher, 1986) como no Brasil, mesmo após vários anos, a co-existência de plantas sadias ao lado de plantas assintomáticas é fato comum nos pomares cítricos. Tal fato contraria a dinâmica espacial, temporal e espaço-temporal resultante da influência de agentes bióticos; 6 - A presença de proteína-RS (RS = relacionada ao estresse), inicialmente designada proteína $\mathrm{RP}(\mathrm{RP}=$ relacionada com a patogênese), constitui indicação quanto à presença de plantas sintomáticas e assintomáticas e não quanto ao envolvimento de um agente biológico específico na ocorrência da doença. De acordo com Berger (1998), a proteína-RS está associada à presença de um fator responsável por estresse na planta. Segundo este autor, a causa do declínio dos citros é a mesma identificada para o declínio de outras espécies arbóreas, qual seja: o estresse. Fatores como desfolha, injúrias por baixas temperaturas, índices elevados de salinidade do solo, reduções do sistema radical por atividades de nematóides e insetos do solo e época inadequada de poda são alguns dos vários fatores responsáveis por estresse. Dentre esses fatores, o autor cita o envolvimento direto de altas concentrações de sais solúveis no solo, resultante de fertilização ou calagem excessivas e déficit ou excesso de umidade. Segundo Castro (1991), já foi estabelecido associação entre injúria no sistema radical e a incidência do declínio dos citros. De acordo com esse autor, há possibilidade de que nas diferentes fases de formação das mudas, fatores desencadeadores de estresse como poda de raízes e tratos culturais inadequados predispõem as plantas ao declínio. Segundo Anderson (1980), poda de raízes de laranjeira 'Valência' enxertada em limoeiro 'Rugoso', com nove anos de idade, causou sintoma de declínio nas plantas, o que corrobora a hipótese do estresse radical e presença de plantas sintomáticas; 7 - A possibilidade da reprodução dos sintomas do declínio dos citros mediante enxertia de raízes é, segundo Berger (1998), interpretada à transferência de ácido abscísico de uma raiz para outra, já que esse hormônio ocorre em níveis elevados em raízes de plantas sob condições de estresse. Tal fato torna praticamente insustentável a defesa do envolvimento de um agente biótico na ocorrência da doença; 8- As ocorrências de desequilíbrio nutricionais são também fatores capazes de ocasionar estresse nas plantas e, dessa forma, contribuir para a ocorrência de sintomas. De acordo com Wutscher (1989), verificou-se a relação direta entre baixas taxas de capacidade de troca catiônica e maior incidência de plantas sintomáticas. Normalmente, a manifestação dos sintomas tem sido mais evidente em solos com teores limitantes de fósforo e potássio, exibindo, por outro lado, altos níveis de cálcio e magnésio e baixos teores de cloro e enxofre. Segundo Wutscher, citado por Berger (1998), nas condições da Flórida, aplicações de grande quantidade de hidróxido de cálcio levou a uma remissão dos sintomas. Sabe-se, entretanto, que dificilmente uma planta afetada por um determinado agente apresentaria recuperação, o que invalida a hipótese do envolvimento de um patógeno; 9- Solos pouco profundos, de baixa fertilidade, com drenagem deficiente, arenosos e capazes de interferir negativamente no desenvolvimento do sistema radical estão relacionados com maior incidência de declínio (Castro, 1991).

\section{A muda cítrica e sua relação com o declínio}

De acordo com Castro (1991) e Berger (1998), o declínio dos citros resulta, aparentemente, de fatores condicionantes de estresse, que se manifestam de forma isolada ou de forma complexa. Todos os aspectos abordados mostram-se pertinentes, porém um aspecto importante fora explorado apenas superficialmente: trata-se da limitada capacidade de desenvolvimento do sistema radical das plantas e os fatores que proporcionam esta limitação. Aparentemente, esse é um dos fatores que mais tem contribuído para o estresse das plantas cítricas e conseqüentemente para a manifestação dos sintomas do declínio dos citros. Plantas com sistema radical escasso ou pouco desenvolvido são as mais afetadas quando sob condições de estresse hídrico, seja pelo excesso ou deficiência. Antes da década de 70, as mudas cítricas eram produzidas em viveiros a céu aberto, sendo que, por ocasião da sua transferência, eram arrancadas sem a existência de terra recobrindo o sistema radical (mudas de raiz nua). Tal prática proporcionava a seleção de mudas com sistema radical pivotante retilíneo e com tamanho adequado. Entretanto, com o vertiginoso crescimento da atividade citrícola a partir da década de 70 , esta prática foi abolida, tendo permanecido a produção de mudas cítricas a céu aberto, porém, substituindo-se a utilização de muda de raiz nua por muda do sistema "em torrão". Tal fato tornou inviável a inspeção do sistema radical dessas plantas, o que, certamente, impossibilitou detectar defeitos nas mesmas, como tortuosidades e divisões indesejáveis. Além disso, o volume de solo que continha o sistema radical era inferior a $1 \mathrm{~L}$ e a muda apresentava-se com a poda de formação por volta de 18 meses. Isso, certamente, contribui para um desequilíbrio entre parte aérea e o sistema radical dessas mudas.

Mediante análise criteriosa, feita nos mais renomados e representativos viveiros do Estado de São Paulo, verificou-se que ainda existe uma variável desse processo que merece atenção, podendo ser substancialmente aprimorada. Atualmente, no processo de produção de mudas de citros são empregados, quase que na sua totalidade, tubetes de $12 \mathrm{~cm}$ de comprimento para a produção das mudas de porta-enxertos. Tal técnica foi adaptada a partir do processo de formação de essências florestais, mais especificamente da cultura de eucalipto. Este procedimento, evidentemente, faculta ao sistema radical pivotante do portaenxerto, em formação no seu interior, uma limitação de crescimento de até $12 \mathrm{~cm}$.

Quando o sistema radical pivotante encontra a parte final do tubete, algumas anomalias morfológicas são desencadeadas e freqüentemente observadas nos viveiros inspecionados: (i) intumescimento na região apical, onde, com o passar do tempo, são emitidas várias ramificações do sistema radical pivotante, sendo que, em alguns casos, quando ocorre maior tempo de permanência do portaenxerto no interior dos tubetes, observa-se a produção de clorofila nessa região de intumescimento (Figura 1); (ii) quando as plantas (portaenxertos) apresentam um tamanho entre 10 a $15 \mathrm{~cm}$, segue-se uma nova etapa no processo de formação das mudas, pois estes são transplanta- 
dos para sacos plásticos com capacidade para 5L de substrato, em média. A partir desse momento, o sistema radical retoma o seu crescimento, concomitantemente ao da parte aérea. Nesta fase, no sistema radical, verifica-se a presença de sub-divisões (raízes secundárias) no ponto de intumescimento da raiz pivotante, formado quando ainda ocupava os tubetes. Essas raízes continuam se desenvolvendo, ficando, portanto, mantida as sub-divisões, como ilustrado em raízes de limoeiro cravo, em vários estádios (Figura 2); (iii) com o desenvolvimento dos porta-enxertos, independente da variedade, a sub-divisão do sistema radical pivotante irá se acentuando na medida em que as raízes forem adquirindo maiores diâmetros. O processo de sub-divisões ocorrido se mantém nas diversas etapas de desenvolvimento das plantas. Estas mudas, quando estão vegetativamente maduras e no estágio designado de palito, são fiscalizadas pelo órgão certificador e, estando isentas de doenças como Cancro cítrico, Gomose de Phytophthora e Clorose Variegada dos Citros, são liberadas para a comercialização; (iv) o citricultor que as adquire, no momento do plantio, corta o fundo do saco plástico com o objetivo de retirar as raízes enoveladas, o que promove, posteriomente, nova sub-divisão do sistema radical pivotante já sub-dividido. A Figura 3 ilustra um saco plástico, cujo fundo foi previamente cortado, contendo muda cítrica, de onde advirão novas subdivisões do sistema radical pivotante, quando são plantadas à campo.
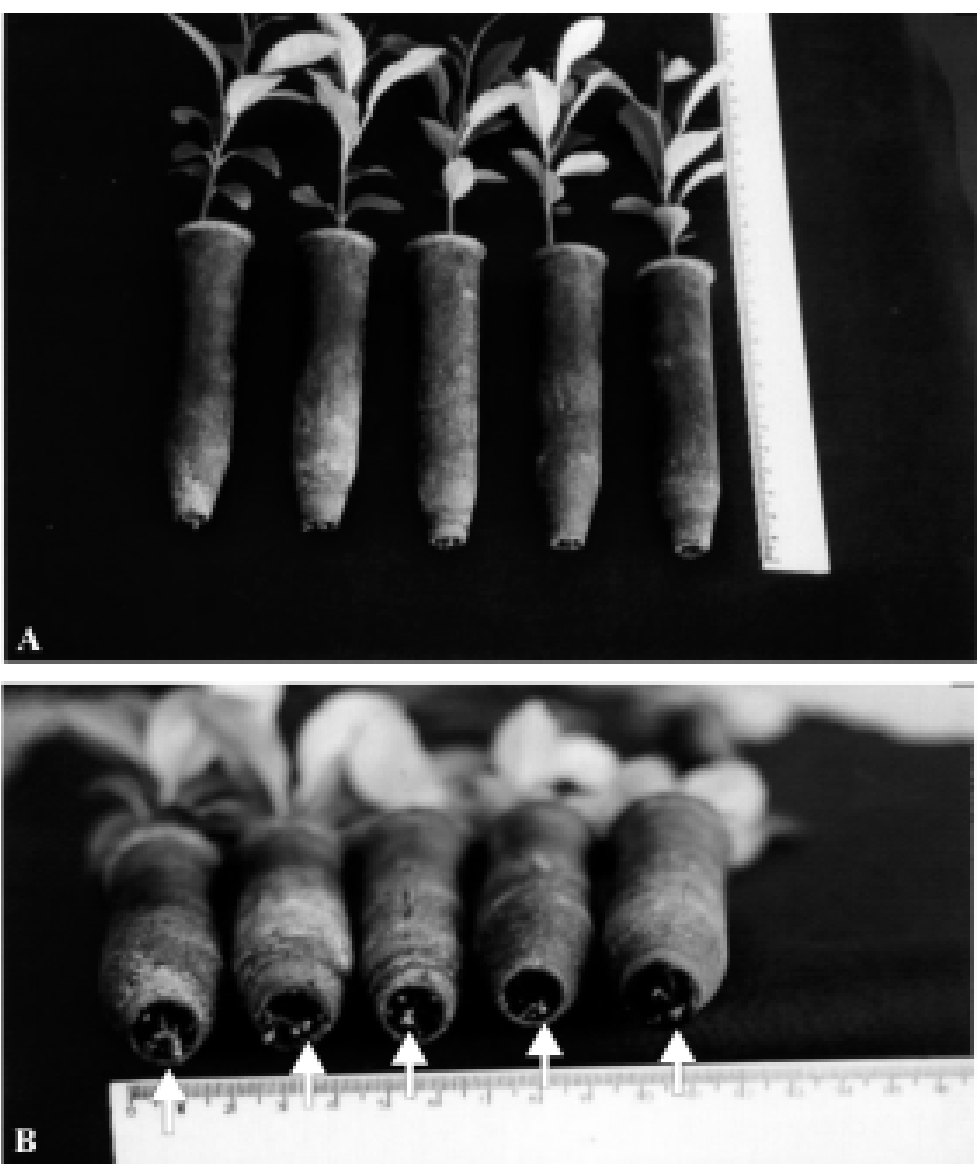

FIGURA 1 - Muda de limoeiro 'Cravo': (A) sendo produzida em tubetes com $12 \mathrm{~cm}$ de comprimento, similar ao utilizado no processo de produção de mudas de essências florestais (eucalipto); (B) presença de raiz pivotante exibindo regiões intumescidas (setas).

Ideal seria que a raiz pivotante das mudas certificadas de citros fosse retilínea e sem divisões, ao menos até o comprimento do saco plástico onde são formadas, após o transplante do porta-enxerto. $\mathrm{Mu}$ das cítricas com essa deformidade apresentam restrições quanto ao crescimento do sistema radical em maiores profundidades do solo, quando plantadas a campo, mesmo que as condições químicas e físicas do mesmo sejam favoráveis. Dessa forma, essas plantas estarão muito mais predispostas ao estresse hídrico e conseqüentemente ao declínio. Devese ressaltar que a parte genética e fitossanitária dos materiais atualmente utilizados são sabidamente superiores àqueles utilizados até recentemente, o que possibilitará a obtenção de maiores produtividades. Entretanto, eventual desequilíbrio entre sistema radical e parte aérea, acentuará ainda mais a condição de estresse, favorecendo o surgimento do declínio nessas plantas.
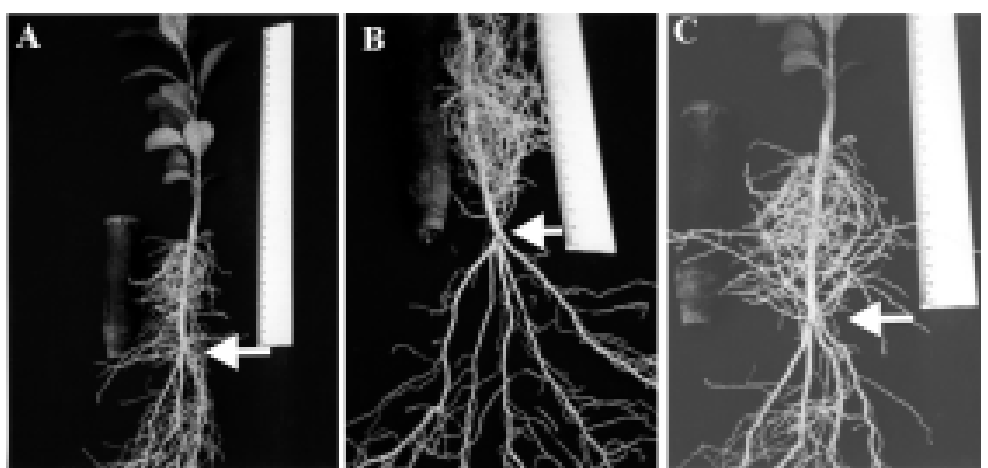

FIGURA 2 - Raízes de muda de limoeiro 'Cravo' produzidas em tubetes de $12 \mathrm{~cm}$ de comprimento: (A) 30 dias após o transplante, exibindo sub-divisões (setas) do sistema radical pivotante, em função das anomalias decorrentes da limitação de crescimento do mesmo; (B) 60 dias após o transplante, exibindo sub-divisões (setas) do sistema radical pivotante, em função das anomalias decorrentes da limitação de crescimento do mesmo; (C) no ponto de enxertia, exibindo subdivisões (setas) do sistema radical pivotante, em função das anomalias decorrentes da limitação de crescimento do mesmo.
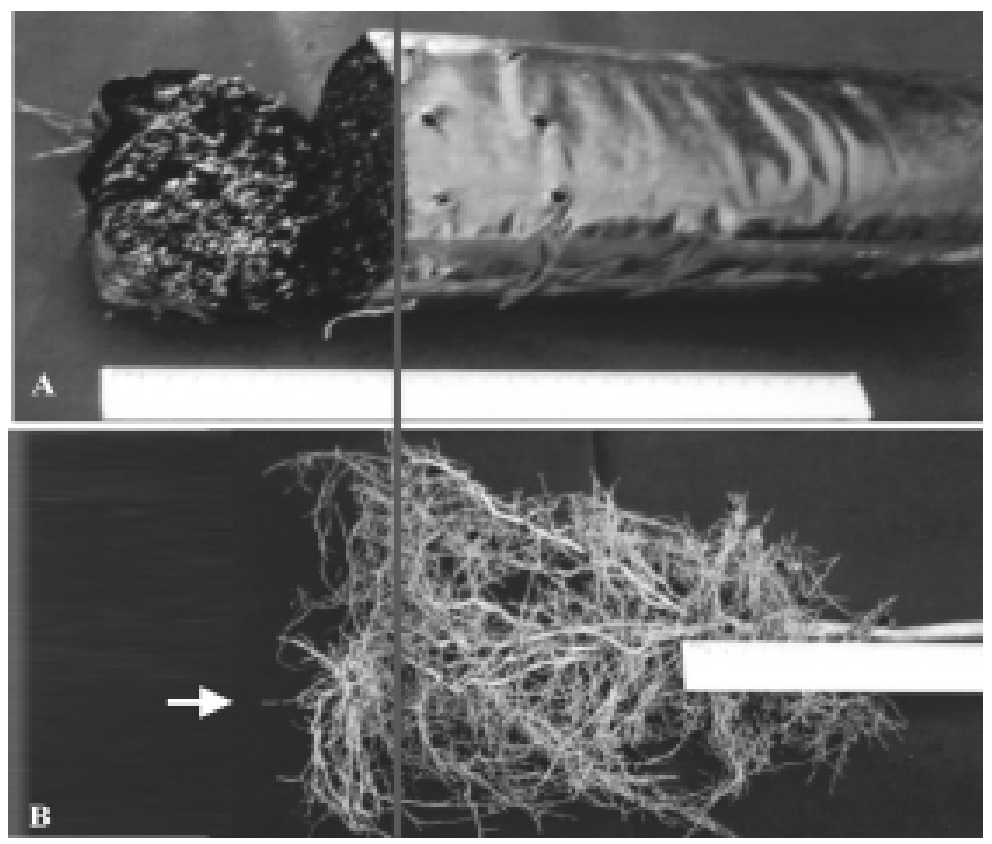

FIGURA 3 - Muda cítrica no momento do plantio: (A) recebendo corte a aproximadamente $2 \mathrm{~cm}$ do fundo do saco plástico para eliminação do enovelamento do sistema radical; (B) presença de enovelamento (seta) que será eliminado com o corte.

Denota-se que as mudas de citros ora produzidas, não apresentam sistema radical adequado, de tal forma que estas, mesmo quando expostas a boas condições de manejo, não atendem as exigências da parte aérea. Dado a esse desequilíbrio e à vulnerabilidade das raízes, amplia-se as condições de predisposição ao estresse de diferentes natureza e, conseqüentemente, ao declínio. Tal fato sugere a necessidade premente de se rever o atual método de produção de porta-enxertos destinados à produção de mudas cítricas.

\section{REFERÊNCIASBIBLIOGRÁFICAS}

ANDERSON, C.A. Effect of trunk girdling, root pruning, and blight on sweet orange fruit quality and leaf mineral composition. Journal of 
the American Society for Horticultural Science, Alexandria, v.15, p.3, 1980 .

BERGUER, R.D. A causa e o controle do declínio dos citros. Revista Laranja, Cordeirópolis, v.19, n. 1, p. 79-90, 1998.

BURNETT, H.C; NEMEC, S.; PATTERSON, M. A review of Florida citrus blight and its association with soil edaphic factors, nutrition and Fusarium solani. Tropical Pest Management, London, v.28, n.4, p.416-422, 1982.

CASTRO, P.R.C. Declínio: Uma anomalia fisiológica dos citros. Revista Laranja, Cordeirópolis, v.12, n.2, p.381-400, 1991.

ROSSETTI, V. Manual ilustrado de doenças dos citros: doenças de causas desconhecidas. Piracicaba: Fealq/Fundecitrus, 2001.270p.

SONODA, R.M.; PELOSI, R.R.; HEBB, J.W. Comparing Rio Grande gummosis and citrus blight incidence on grapefruit on Swingle citrumelo rootstock. Proceeding of the Florida State Horticultural Society, Winter Haven, v.105, p.28-32, 1992.

SWINGLE, W. T.; WEBER, H. J. The principle disease of citrus fruits in Florida. Florida; USDA, 1896. (Bulletin, n.8).
TUBELIS, A.; PRATES, H.S.; SALIBE, A.A. Comportamento do declínio nos pomares cítricos do Estado de São Paulo. Laranja, Cordeirópolis, v.1, n. 9, p. 187-199, 1988.

TUCKER, D.P.H.;LEE, R.F.; TIMMER,L.W.;ALBRIGO,L.C.; BRLANSKY, R.H. Experimental transmission of citrus blight. Plant Disease, St. Paul, v. 68, n. 1, p. 979-980, 1984.

WUTSCHER, H.K. Comparison of soil, leaf and feeder root nutrient levels in the citrus blight-free and citrus blight affected areas of a 'Hamlin' orange grove. Proceedings of the Florida Horticultural Society, Winter Haven, v. 99, p.74-77, 1986.

WUTSCHER, H.K. Soil pH and extractable elements under blight-affected and healthy citrus trees on six Florida soils. Journal of the American Society of Horticultural Science, Alexandria, v.114, n.4, p.611-614, 1989.

YOKOMI, R.K.; GARNSEY, S.M.; YOUNG, R.H.; GRIMM, G.R. Declines of unknown etiology. In: IOCV CONFERENCE, 9., 1984. Riverside Proceedings...Riverside: International Organization of Citrus Virologists, 1984. p. 260-269. 